taken were unjustifiable on grounds of radiological protection, while some that were worth while, such as taking stable potassium iodide in the month after the accident to prevent uptake of radioiodine by the thyroid, were implemented by only about a fifth of the population.

Although the IAEA project found numerous health problems unrelated to Chernobyl, it found no health effects, other than psychological ones, that could be confirmed as directly attributable to radiation. This is not surprising for several reasons. The project's remit excluded those likely to have received the highest doses - namely, rescue workers, workers at the plant itself, and those who had been evacuated. Only about 1350 people currently living in the area and readily available were included in the survey. This number is big enough to identify major discrepancies between contaminated and control villages in the prevalence of common disorders or in the average value of variables such as haemoglobin concentration, but it is too small to detect a modest increase in cancers or other serious but rare disorders. Furthermore, many effects would not yet have had time to appear. Other studies of the effects of exposure to radiation have found the highest relative increase for leukaemia occurring within five years of exposure, ${ }^{2}$ but for many other cancers increases even five to 10 years after exposure are modest compared with those in later years. ${ }^{3}$ Hypothyroidism may also take many years to manifest itself.

Risk estimates based on the experience of other exposed populations provide a rough guide to the likely ultimate toll from Chernobyl in those continuing to live in contaminated areas. ${ }^{4}$ With IAEA project estimates of dose in the 70 years after the accident and a dose rate reduction factor of 2 for cancers other than leukaemia, the estimated increase in the overall risk of fatal cancer is about $2-4 \%$ in the contaminated area, with the possibility of larger proportionate increases in the incidence of thyroid cancer and also in some cases of hypothyroidism. Accurate forecasting is, however, difficult. Official Soviet procedures for dose assessment often resulted in overestimates, typically by factors of 2-3. The largest doses are thought to have been thyroid doses resulting from shortlived radioiodines. These had completely decayed before the IAEA project, thus preventing any refinement of initial Soviet estimates. Furthermore, although much is known about the effects of radiation, the Chernobyl experience differs from other events that have been studied intensively to date: a substantial proportion of the dose was from internal irradiation, dose rates were low, and thyroid doses were of a mixture of shortlived radioiodines. In view of all these uncertainties monitoring of the population, such as has started in the Ukraine, ${ }^{5}$ seems desirable even though the data may require careful interpretation.

The IAEA team found Soviet scientists and doctors battling against a complex administration with inadequate resources, often in isolation from recent scientific developments, and in an atmosphere of public mistrust. They need our patience, sympathy, and any real help we can give them.

SARAH C DARBY Staff Scientist GILLIAN K REEVES

ICRF Cancer Epidemiology Unit, Statistician

Radcliffe Infirmary, Oxford OX2 6HE

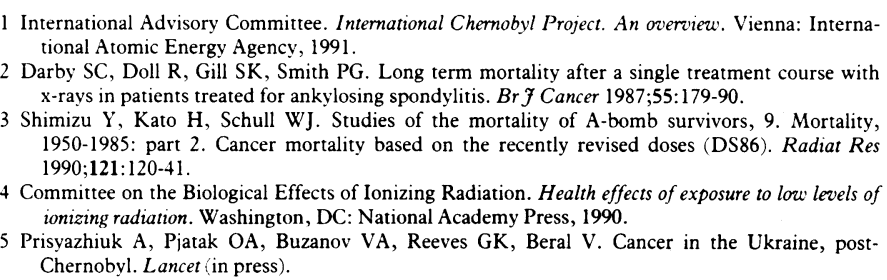

1 International Advisory Committee. International Chernobyl Project. An overview. Vienna: Intern

tional Atomic Energy Agency, 1991.
Darby SC, Doll R, Gill SK, Smith PG. Long term mortality after a single treatment course with $x$-rays in patients treated for ankylosing spondylitis. Br $\mathcal{F}$ Cancer 1987;55:179-90.

3 Shimizu Y, Kato H, Schull WJ. Studies of the mortality of A-bomb survivors, 9. Mortality, 1950-1985: part 2. Cancer mortality based on the recently revised doses (DS86). Radiat Res 1990;121:120-41.

Committee on the Biological Effects of Ionizing Radiation. Health effects of exposure to low levels of ionizing radiation. Washington, DC: National Academy Press, 1990.

Prisyazhiuk A, Piatak OA, Buzanov VA, Reeves GK, Beral V. Cancer in the Ukraine, postChernobyl. Lancet (in press).

\title{
Artificial blood
}

\section{Mostly on the drawing board}

The term "artificial blood" is loosely applied to substitutes designed to replace the oxygen carrying capacity of human red cells. Clinically acceptable solutions for replacing plasma volume have been available for many years, but the quest for a replacement to red cell transfusions continues. Its potential advantages are considerable - no risk of transmissible disease, no need to cross match, a shelf life of years rather than weeks, and an unlimited supply manufactured on demand.

Research has focused on two main approaches: developing synthetic oxygen carrying compounds and producing solutions of haemoglobin. Progress has been slow, for two main reasons - toxicity and brief intravascular dwell times. ${ }^{1-5}$

The development of genuinely artificial blood substitutes began dramatically with the finding that submerged mice survived in oxygenated solutions of perfluorocarbon. ${ }^{6}$ Perfluorocarbons are biochemically inert and in their liquid form have a high solubility for oxygen, proportional to the partial pressure of oxygen. Their main disadvantages are the need for very high inspired oxygen concentrations (with the attendant dangers of oxygen toxicity) and their insolubility in water. This is overcome by producing emulsions, but these are unstable and must be stored frozen at $-20 \mathrm{C}$. Reconstitution, warming, oxygenation, and the administration of a test dose to assess tolerance are then required before the solution is ready for intravenous infusion. The reticuloendothelial system quickly clears the microdroplets of emulsion from the circulation, resulting in a short intravascular half life of only 8-24 hours. Excretion occurs over seven days, mostly through the lungs. Uptake by the reticuloendothelial system and the possibility of "immune blockade" has raised concerns about safety. Intravenous infusion of certain emulsions also seems to activate complement and stimulate the release of cytokines, resulting in transient "allergic" reactions such as hypotension, leucopenia, and chest pain.

Fluosol DA20 was the first perfluorocarbon produced commercially for human use, delivering $5 \mathrm{ml}$ oxygen $/ 100 \mathrm{ml}$ perfluorocarbon at $100 \%$ oxygen, $^{7}$ and animal studies also showed that Fluosol DA20 could sustain life at "zero" packed cell volume. Unfortunately, in surgical patients with acute severe anaemia (haemoglobin $30-40 \mathrm{~g} / \mathrm{l}$ ) who could not be given transfusions for religious reasons, Fluosol DA20 was ineffective in delivering sufficient oxygen to sustain life at the doses permitted $(40 \mathrm{ml} / \mathrm{kg}) .{ }^{89}$ Another use has, however, been found for it. Fluosol DA20 reduces ischaemic damage to the myocardium during percutaneous transluminal coronary angioplasty (presumably because of its small particle size and low viscosity at low rates of blood flow in small blood vessels),${ }^{+5}$ and is licensed for this indication in the United States. Although not licensed in Britain, it has been used successfully on a named patient basis. 
Other perfluorocarbons may eventually be shown to substitute satisfactorily for blood. One such compound is perfluoroctobromide, which has five times the oxygen carrying capacity of Fluosol DA20 and can be stored at $4^{\circ} \mathrm{C}$. It has been successfully tested in dogs, and the results of studies in humans are awaited.

A solution of haemoglobin is particularly attractive as a blood substitute because it retains some of the essential characteristics of blood in carrying an equivalent amount of oxygen with normal inspired air, unloading oxygen satisfactorily in the tissues, and contributing to colloid oncotic pressure. Extracting haemoglobin from red cells to produce a cell free oxygen carrying solution would seem relatively simple, but the first red blood cell haemolysates caused acute renal failure, ${ }^{10}$ and interest waned until the red cell stroma was shown to be the main nephrotoxic agent. ${ }^{11}$ Early clinical studies of stroma free haemoglobin, however, showed that even "pure" stroma free haemoglobin is nephrotoxic and hypotensive. ${ }^{12}$

Several other problems exist with stroma free haemoglobin. Once outside the red cell the haemoglobin tetramer rapidly dissociates to dimers, which are excreted in the urine. (This results in an intravascular half life of only two to four hours.) The loss of 2,3-diphosphoglycerate results in a high oxygen affinity. Although much effort has been spent on "normalising" haemoglobin chemically, such solutions may be used only at concentrations of $70 \mathrm{~g} / \mathrm{l}$ because of their high colloid oncotic pressure. Another problem is that haemoglobin slowly oxidises to methaemoglobin unless stored frozen, under nitrogen, or in a vacuum. There are also concerns about immune blockade after large infusions, with possibly increased susceptibility to infection. ${ }^{13}$ Despite these limitations solutions of stroma free haemoglobin can sustain life in animal models even at a zero packed cell volume and show acceptable oxygen transport characteristics in vivo. ${ }^{21+}$ They are therefore serious contenders as short term blood substitutes.

Because of technical difficulties it was not until the 1980s that a new generation of commercial haemoglobin products became available for clinical trials. Poly SFH-P was produced by polymerising pyridoxalated stroma free haemoglobin with glutaraldehyde, a process that is partially virucidal and reduces the colloid oncotic pressure, enabling the production of a solution of "normal" haemoglobin concentration (140 $\mathrm{g} / \mathrm{l})$.

The first studies in humans began in 1989: of six people given $0.25 \mathrm{~g} / \mathrm{kg}$ (equivalent to $120 \mathrm{ml}$ blood), one had a mild allergic reaction, but otherwise no adverse biochemical, renal, or haematological effects occurred. ${ }^{35}$ In further studies, however, patients given infusions postoperatively suffered allergic reactions with flu-like symptoms and chest tightness lasting some two hours and the trials were cancelled (J C Fratantoni, international symposium on blood substitutes, Montreal, 1991). ${ }^{16}$

Shortly after this setback, the US Food and Drug Administration called a closed meeting of companies researching into stroma free haemoglobin. (This unusual step reflected the lack of scientific peer review and open scientific exchange of information between the various research groups, resulting from understandable, but excessive, commercial secrecy.) The meeting was followed by specific guidance from the Food and Drug Administration's Center for Biologics Evaluation and Research on what safety tests would be required before licensing. ${ }^{17}$

Earlier this year SFH, a glutaraldehyde polymerised bovine haemoglobin, was granted trial status in the United Statespresumably on the basis of the new Food and Drug Administration regulations and the report of successful infusion in volunteers in Guatemala $\left.{ }^{16}\right)$. This product was developed despite concerns about the possible immunogenicity of "foreign" haemoglobin. In animals, repeated exposure to heterologous haemoglobin can cause severe anaphylactic reactions, ${ }^{2}$ and when adverse reactions were reported in studies in humans further clinical studies were suspended (J C Fratantoni, international symposium on blood substitutes, Montreal, 1991). The main problem with these compounds is the lack of a suitable animal test model - the only reliable safety data seem to come from humans. It now looks as if commercial application of stroma free haemoglobin will be delayed by several years while the problems of safety are addressed further.

Encapsulating haemoglobin inside synthetic lipid membranes (liposomes) to produce artificial red cells has been another attempt to mimic blood. ${ }^{2}$ Although this avoids the problems associated with removing haemoglobin from its natural environment within the red cell, the technical problems of formulating a stable microencapsulated solution have been formidable. High pressure extrusion systems have been developed to generate satisfactory liposomes, ${ }^{18}$ but further modifications of the lipid envelope are necessary to improve biocompatibility and the short intravascular half life (4-20 hours). Incorporating carbohydrates, cholesterol, and phospholipids increases biocompatibility, and it is now possible to produce liposomes robust enough to be freeze dried for long term storage, ${ }^{19}$ which may reduce the problem of oxidation to methaemoglobin. As yet materials are not sufficiently advanced for clinical trials.

Using human (or even bovine) blood as the source of haemoglobin is not without problems. Apart from the possibility of contamination with infectious agents, the supply of human blood is limited, and only outdated blood can be spared at present. In countries where red cells are in surplus and blood supplies are dominated by the need for plasma for factor VIII and albumin, diverting surplus red cells may become acceptable. It is doubtful, however, whether the supply could satisfy the likely demand once a safe substitute became available since there is continued pressure from the public for the unattainable goal of "zero risk" transfusions. In these circumstances haemoglobin solutions might well substitute for the one to two unit surgical transfusions (about half of all blood transfused) which could be diverted to the manufacture of haemoglobin solutions.

This has encouraged biotechnological approaches. The production of recombinant haemoglobin in micro-organisms is now possible, ${ }^{20}$ as is the creation of transgenic animals to produce "human" haemoglobin. ${ }^{21}$ By genetic engineering, the $\alpha$ and $\beta$ haemoglobin chains can be modified so that they combine to produce a stable tetramer with acceptable oxygen affinity without the need for chemical modification. This is an important technical advance for bulk manufacture, and products are close to clinical trial; it remains to be seen whether the toxicity associated with red cell extracted haemoglobin solutions is avoided. The breeding of transgenic pigs, ${ }^{22}$ which produce human as well as porcine haemoglobin in their red cells, raises the possibility of an alternative large scale supply for the manufacture of haemoglobin solutions. The substitution of pig donors for human donors raises the possibility of religious and animal rights objections in addition to the usual problems with haemoglobin solutions.

No clinically acceptable blood substitutes are currently available for routine use in short term blood replacement. Although perfluorocarbons and haemoglobin derivatives are effective in laboratory studies and in experimental animal models, their short intravascular half life limits their use to short term or emergency replacement. Even then it is debatable whether their additional oxygen carrying capacity 
gives them much of an advantage over conventional volume replacement with crystalloids or colloids unless extreme anaemia prevails. Concerns about safety (either immediate allergic responses or long term effects) limit the maximum clinical doses acceptable even in trials, and this remains the most important problem to be resolved-as it has for the past 50 years.

S J URBANIAK

Regional Director,

Aberdeen and North East of Scotland Blood Transfusion Centre,

Royal Infirmary, Aberdeen AB9 2ZW

I Chang TMS, Gever RP, eds. Blood substitutes. New York: Marcel Dekker, 1989.

2 Chang TMS. The use of modified hemoglobin as an oxygen carrying blood substitute. Transfusion Medicine Reriews 1989;3:213-8.

3 Zuck TF. The quest for a blood substitute. In: Nance SJ, ed. Transfusion medicine in the 1990's. Arlington: A A B B, 1990:181-99.

4 Faithfull NS. Fluorocarbons: current status and future applications. Anaesthesia 1987:42:234-42.

5 Lowe KC. Synthetic oxygen transport fluids based on perfluorochemicals: applications in medicine and biology. Vox Sang 1991;60:129-40.

6 Clark LC, Gollan F. Survival of mammals breathing organic liquids equilibrated with oxygen a atmospheric pressure. Science 1966;152:1755-7.

7 Mitsuno T, Ohyanagi H, Naito R. Clinical studies of a perfluorochemical whole blood substitute (Fluosol F-DA): summary of 186 cases. Ann Surg 1982;195:60-9.
8 Gould SA, Rosen AL, Sehgal LR, Langdale LA, Krause LM, Ruce CL, et al. Fluosol DA as a red cell substitute in acute anemia. $N$ Engl 7 Med 1986;314:1653-6.

9 Spence RK, McCoy S, Constable J, Norcross ED, Pello MJ, Alexander JB, et al. Fluosol DA-20 in the treatment of severe anaemia: randomised controlled study of 46 patients. Crit Care Med 1990; 18:1227-30

10 Amberson WR, Jennings JJ, Rhodes CM. Clinical experience with hemoglobin-saline solution. 7 Appl Physiol 1949;1:409-89.

11 Rabiner SF, Helbert JR, Lopes H, Friedman LH. Evaluation of stroma-free hemoglobin for use as a plasma expander. $\mathcal{F}$ Exp Med 1967;126:1127-42.

12 Savitsky JP, Doczi J, Blacke J, Arnold JD. A clinical safety trial of stroma-free hemoglobin $\mathrm{D}$ Clin Pharmacol Ther 1978;23:73-80.

13 Litwin MS, Walter CW, Ejarque P, Reynolds ES. Syneristic toxicity of gram-negative bacteria an free colloidal hemoglobin. Ann Surg 1963;157:485-93.

14 Gould SA, Rosen AL, Sehgal LR, Sehgal HL, Moss GS. Polymerised pyridoxalated hemoglobin efficacy as an O carrier? F Trauma 1986:26:903-8.

15 Moss GS, Gould SA, Rosen AL. Results of the first clinical trial with a polymerised hemoglobing

solution (abstract). Biomater Artif Cells Artif Organs 1989;17:633.
16 Winslow RM, interviewed by R Poole. Slow going for blood substitutes. Science 1990;250:369-71 $\frac{\bar{\sigma}}{\bar{D}}$

17 Fratantoni JC. Points to consider in the safety evaluation of hemoglobin-based oxygen carriers CBER report. Transfusion 1991:250:1655-6.

18 Rabinovici R, Rudolf AS, Ligler FS, Yue TL, Feuerstein G. Liposome-encapsulated hemoglobin an oxygen carrying fluid. Circ Shock 1990; 32:1-17. an oxygen carrying fluid. Circ Shock 1990;32:1-17.
19 Rudolf AS, Cliff RD. Dry storage of liposome encapsulated hemoglobin: a blood substitute.
Crvobiology 1990;27:585-90. Cryobiology 1990;27:585-90.

20 Wagenbach M, O'Rourke K, Vitez L, Wieczorek A, Hoffman S, Durfee S, et al. Synthesis of wild type and mutant human hemoglobins in saccharomyces cerevisiae. Biotechnology 1991;9:57-61 21 Behringer RR, Ryan TM, Reilly MA, Askura T, Palmiter RD, Brinster RL, et al. Synthesis of
functional hemoglobin in transgenic mice. Science 1989;245:971-3.

22 Blood and biotechnology. International Blood/Plasma News 1991;8:146-7.

\section{The health strategy and the hole at the centre}

\section{Central government needs a mechanism for collaboration}

Successive governments have failed to articulate a policy for health as distinct from health services. The NHS has become a catch all for all aspects of health and health care and as a result is expected to deliver the undeliverable. If the government's health strategy ${ }^{1}$ is to remain durable beyond the life of the present secretary of state for health there needs to be both a mechanism for considering health in general and a culture that supports such a development and will enable it to become embedded in the organisational life of Whitehall. How the health strategy is implemented is therefore a central issue that will determine its ultimate fate.

In its strategy the government acknowledges the need for central government departments to work together for the greater good of the public's health and for suitable joint working between central government and other agencies, notably local authorities. The logic is impeccable, but the proposed mechanisms for securing these ends do not inspire confidence. The Department of Health has not been notably successful in promoting policies for health, as distinct from health services. Remember Barbara Castle's "red book" on prevention and health, that appeared in 1976?"

Coordination of policy covering the frontiers of different departments and agencies is a major challenge to our governmental system. Cabinet government is meant to evolve a corporate strategy, but central government does not naturally operate corporately. The Whitehall "village" makes a great pretence of taking collaboration seriously, ${ }^{34}$ and in one sense it succeeds. Whitehall is riddled with interdepartmental committees, but these are designed less to promote cross departmental working than to provide a mechanism for defending departmental interests and to prevent them from being diluted or lost sight of. They are a negative force to preserve the status quo rather than an instrument for policy change. On top of this is an almost pathological distaste for long term problem solving and a preoccupation with issues of immediate concern to ministers and their survival.

The most developed example of an ill fated attempt to establish effective cross departmental working was the JASP initiative (Joint Approach to Social Policy), which enjoyed a short life in the mid 1970s. ${ }^{5-7}$ This strategic forum was a serious attempt to break the Whitehall mould, but it withered for want of ministerial support as ministers lost interest in $\bar{\delta}$ forum from which their individual departments derived littlæ direct benefit. ${ }^{8}$

An initiative similar to JASP might usefully broaden the debate about health, and, conceivably, the health strateg $\overrightarrow{0}$ steering group could provide the basis for such a venture But whether it should reside in the Department of Health is arguable. Should the Department of Health be even trying to give a lead?' The department's primary responsibility is fo the NHS, and as long as its attention is devoted to problems arising within the service there is little chance of it attendin\& to health in its broader sense. ${ }^{10}$ The urgent will forever driv $\vec{E}$ out the important. Also, large tracts of public policy affecting health fall not within the Department of Health's grasp but within that of the Department of the Environment - which might be a more appropriate department to assume the health mantle.

The precise mechanism of filling the hole at the centre matters less at this stage than the recognition that the hole needs to be filled effectively if a strategy for health is tक survive. The New Zealand government has acknowledged the realities of organisational life and has separated the funding and management of public health services from persona $\$$ health services." We need to consider whether a similat arrangement is not also necessary in the United Kingdom Mere exhortations to collaborate are not enough to secur\&్ action.

Professor of Health Policy and Management Director,

Nuffield Institute for Health Services Studies,

University of Leeds,

Leeds LS2 9PL

1 Secretary of State for Health. The health of the nation. London: HMSO, 1991. (Cmnd 1523.) Department of Health and Social Security. Prevention and health: everybody's business. Londori HMSO, 1976

3 Heclo H, Wildavsky A. The private government of public money. London: Macmillan, 1974 4 Hennessy P. Whitehall. London: Secker and Warburg, 1989.

5 Central Policy Review Staff. A joint framework for social policies. London: HMSO, 1975.

6 Challis L, Henwood M, Klein R, Plowden W, Webb A, Whittingham P, et al. foint approaches social policy. Cambridge: Cambridge University Press, 1988.

Blackstone T, Plowden W. Inside the think tank. London: Heinemann, 1988.

8 Kaufman G. How to be a minister. London: Sidgwick and Jackson, 1980. carrison S, Hunter DJ, Johnston I, Nicholson N, Thunhurst C, Wistow G. Health befor
care. London: Institution for Public Policy Research, 1991. (Social Policy Paper No 4.) 0 Smith A. A national health service and the public health. Public Health 1988;102:227-36. 11 Ministry of Health. Your health and the public health. Wellington: Ministry of Health, 1991 